Check for updates

Cite this: RSC Adv., 2018, 8, 15621

Received 1st March 2018 Accepted 13th April 2018

DOI: $10.1039 / c 8 r a 01807 c$

rsc.li/rsc-advances

\title{
Simple and rapid monitoring of doxorubicin using streptavidin-modified microparticle-based time- resolved fluorescence immunoassay $\dagger$
}

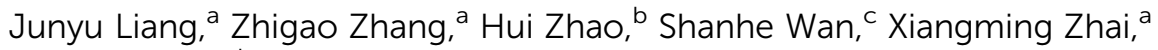 \\ Jianwei Zhou, ${ }^{d}$ Rongliang Liang, ${ }^{a}$ Qiaoting Deng, ${ }^{a}$ Yingsong Wu $\mathrm{W}^{\star a}$ \\ and Guanfeng Lin (D) *e
}

\begin{abstract}
Developing a simple analytical method suitable for therapeutic drug monitoring in a clinical setting is key to establishing guidelines on accurate dose administration and the advancement of precision medicine. We devised a simple rapid analytical method through the combination of streptavidin-modified microparticles and a time-resolved fluorescence immunoassay for therapeutic drug monitoring. The analytical performance of this method was investigated and validated using clinical samples. By determination of doxorubicin concentration, the proposed assay has shown a satisfactory linear range of detection (3.8-3000 $\mathrm{ng} \mathrm{mL}^{-1}$ ) with a limit of detection of $3.8 \mathrm{ng} \mathrm{mL} \mathrm{g}^{-1}$ and an $\mathrm{IC}_{50}$ of $903.9 \mathrm{ng} \mathrm{mL}^{-1}$. The intra and inter-assay coefficients of variation were $4.12-5.72 \%$ and $5.48-6.91 \%$, respectively, and the recovery was acceptable. The applicability of the proposed assay was assessed by comparing the determined results with those measured by LC-MS/MS, presenting a satisfactory correlation $\left(R^{2}=\right.$ 0.9868). The proposed assay, which shows satisfactory analytical performance, has great potential for application in the field of TDM in the future.
\end{abstract}

\section{Introduction}

Cancer is a leading cause of death worldwide. An estimated 4.2 million new cancer cases and 2.8 million cancer deaths occurred in China in 2015., In the next few years, the global cancer burden will continue to rise owing to increasing cancer diagnoses because of the aging population and increased susceptibility to cancers. Consequently, the demand for chemotherapy treatments will increase to at least twice that of the current level over the next 10 years. It is certain that chemotherapy will remain an essential treatment for cancer patients. However, most of the commonly used anticancer drugs have some disadvantages that limit their use, such as: (i) a narrow therapeutic window requiring more rigid drug

\footnotetext{
${ }^{a}$ Institute of Antibody Engineering, School of Laboratory Medicine and Biotechnology, Southern Medical University, Guangzhou, China. E-mail: wg@smu.edu.cn; Fax: +8620-37247604; Tel: +86-20-62789355

${ }^{b}$ Department of Plastic and Aesthetic Surgery, Third Affiliated Hospital, Sun Yat-Sen University, Guangzhou, China

'Guangdong Provincial Key Laboratory of New Drug Screening, School of Pharmaceutical Science, Southern Medical University, Guangzhou, China

${ }^{d}$ Guangzhou Darui Biotechnology Co. LTD, Guangzhou, China

${ }^{e}$ Experimental Center of Teaching and Scientific Research, School of Laboratory Medicine and Biotechnology, Southern Medical University, Guangzhou, China. E-mail: lingf@smu.edu.cn; Fax:+86-20-37247604; Tel: +86-20-62789356

$\dagger$ Electronic supplementary information (ESI) available. See DOI: $10.1039 / \mathrm{c} 8 \mathrm{ra01807c}$
}

administration to balance anti-cancer efficacy and side effects; (ii) high individual variability in drug metabolism and distribution making it difficult to achieve effective therapeutic concentration; (iii) no available practical guidance or suitable parameters to evaluate the clinical efficacy and a lack of standardized regimes for long-term application; (iv) dose-dependent side effects. ${ }^{3}$

Inaccurate clinical dosing of anticancer drugs prevails throughout the world, and the situation in China is particularly severe. Therapeutic drug monitoring (TDM), first proposed in the 1980s, which involves the measurement and interpretation of systemic drug concentrations in biological fluids and the individualization of drug dosage or schedules to maximize therapeutic effects and minimize toxicity, ${ }^{4}$ has been applied in antibiotics, ${ }^{5}$ antiepileptics, ${ }^{6}$ antipsychotics, ${ }^{7}$ and anticancer agents for decades. ${ }^{8}$ TDM of anticancer drugs has been discussed for many cases, ${ }^{\mathbf{9 1 0}}$ and findings have shown that TDM of anticancer drugs helped to make timely dose adjustments during the period of chemotherapy. It was also indicated that human intervention in dosing management elevated clinical efficacy by minimizing side effects and enhancing precise individualized administration. In the push for precision medicine and personalized treatment, establishing guidelines for individualized dosing is imperative and urgently needed to achieve precision medicine under the guidance of drug monitoring. 


\section{A}
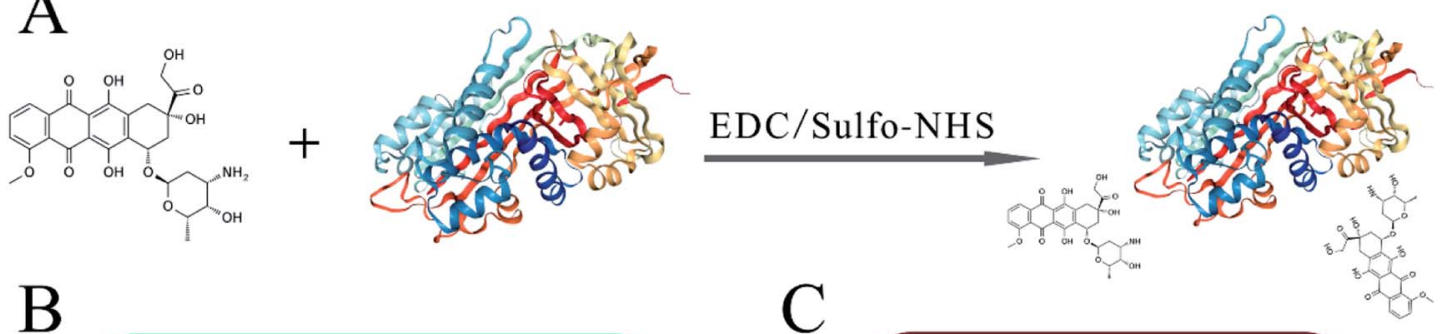

B

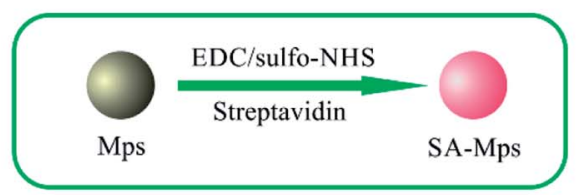

D
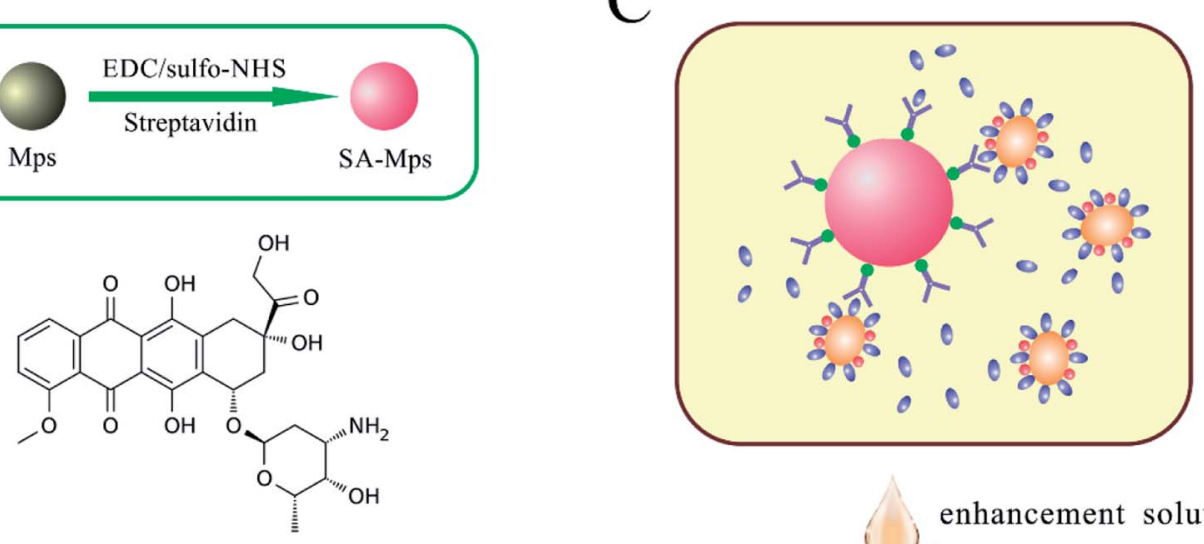

$\mathrm{E}$
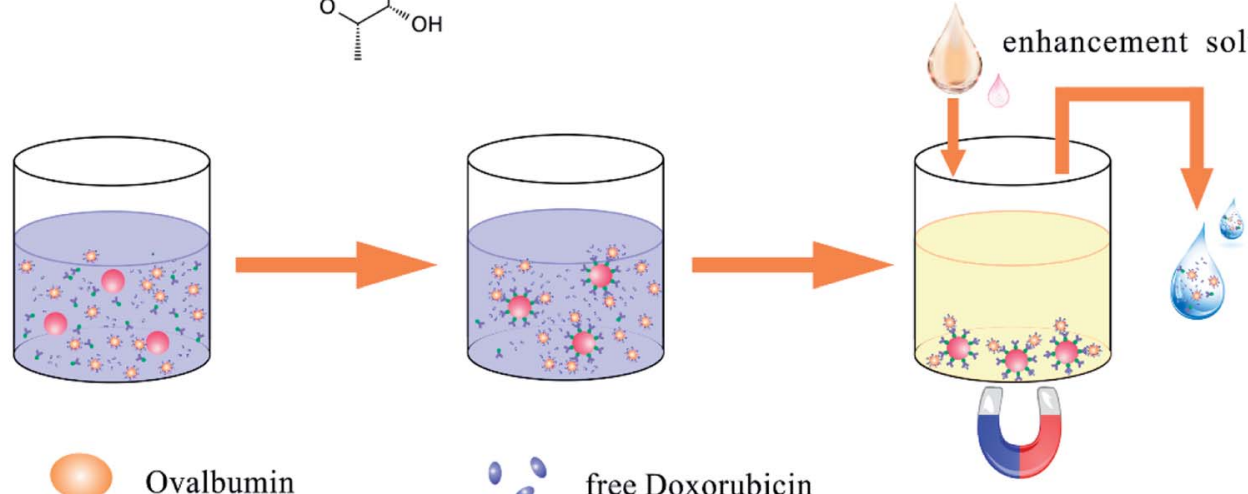

Ovalbumin

free Doxorubicin

Biotinylated antibody

- Europium-chelate

Fig. 1 Schematic illustration of SA-MP-based TRFIA. (A) Labeling of DOX-conjugated ovalbumin complex. (B) Synthesis of SA-MPs. (C) Reaction mode of proposed assay. (D) Structure of doxorubicin. (E) Assay procedure for SA-MP-based TRFIA in detection of DOX.

Doxorubicin (DOX, Adriamycin), a typical anthracycline antibiotic, is widely used for treating various cancers, in particular breast, ovarian, leukemia, prostate, brain and lung cancers. ${ }^{11}$ In addition, DOX is one of the frontline drugs currently used for adjuvant chemotherapy treatment of advanced breast cancer. However, long-term clinical use of DOX is hampered by its multidirectional cytotoxic effects, with cardiotoxicity being the most prominent. Although the current evidence is insufficient to mandate TDM of DOX in routine practice, ${ }^{12}$ many cases have indicated that TDM of DOX in biological fluids can reduce side effects and optimize clinical efficacy. ${ }^{3,9,10,13,14}$ To date, a number of analytical methods such as high performance liquid chromatography (HPLC), ${ }^{15}$ high performance liquid chromatography mass spectroscopy/mass spectroscopy (LC-MS/MS) alone ${ }^{16,17}$ or combined with capillary electrophoresis $(\mathrm{CE})^{18}$ or optical LED imaging, fluorescence spectroscopy, ${ }^{19,20}$ electrochemical sensors ${ }^{21}$ and bioluminescent sensors, ${ }^{22}$ have been developed for determination of DOX in biological samples. However, all these analytical methods are inappropriate for TDM of DOX chemotherapy in daily clinical practice. The methods have their individual merits, however most of them are not available or practical for daily use in a clinical laboratory owing to the high capital cost and high technical requirements. In addition, most of them require expensive detection equipment and a professional operator.

As a widely used testing technology for daily clinical practice, TRFIA is an ultrasensitive tool that has been shown to be highly specific and sensitive in many cases of clinical diagnosis. With its favorable high precision, it is widely used in different quantitative detections and generally recognized in the field of laboratory medicine. The lanthanide chelates applied in TRFIA have exceptionally large Stokes shift $(>200 \mathrm{~nm})$, decay time (>500 ns) and quantum yield, which make it possible to eliminate background interference from nonspecific fluorescence. Europium is one of the most frequently used lanthanide chelates and it was used here to label the competitive antigen. Magnetic microparticle-based TRFIA is a development of general TRFIA that has been reported for different applications 


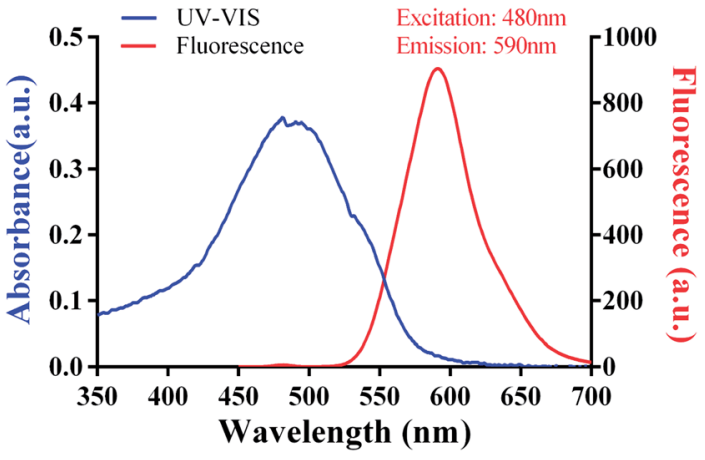

Fig. 2 Fluorescence characteristics and UV-VIS spectrum of doxorubicin.

such as cancer, ${ }^{23,24}$ infectious disease, ${ }^{25,26}$ and prenatal screening $^{27}$ and fits well in routine detection owing to advantages such as high precision, ultra-sensitivity, and its simple automated procedure. In addition, magnetic microparticles have high specific surface area and can be rapidly collected and separated from superfluous analytes in a magnetic field, shortening reaction time by increasing the fluid exchange and automation of the washing and separation process.

Herein, we established a promising TRFIA detection system using magnetic microparticles as a carrier for streptavidin (SA). Taking advantage of the versatile biotin-streptavidin system (BSAS), ${ }^{28}$ a classical signal amplified system, which has been widely used in biomedical detection, we were able to improve the sensitivity of the detection as SA-MPs could bind more antibodies through the strong biotin-streptavidin interaction. ${ }^{29}$ Thus, we have developed a novel TRFIA determination system, which was applied in TDM and was validated for daily detection in routine TDM. The study involved measurement of parameters such as sensitivity, precision, recovery, linearity, and feasibility.

\section{Materials and methods}

\subsection{Ethics}

All experiments were performed in compliance with relevant laws and followed by institutional guidelines of Southern medical university (Guangzhou, China). The BALB/c mice used in this study were obtained from the Experimental Animal Center, Southern Medical University (Guangzhou, China). This study was approved and registered (Grant No. 44002100013613) by the laboratory animal welfare and ethics committee of Southern Medical University (Guangzhou, China). The care and use of the animals conformed to the Institutional Animal Ethics Committee guidelines. The experimental materials and solutions used are listed in the ESI. $\dagger$

\subsection{Preparation of DOX-conjugate immunogen and coating antigen}

For immunization and preparation of anti-DOX antibody, conjugation to the carrier protein $\mathrm{KLH}$ was required. $20 \mathrm{mg}$ of $\mathrm{KLH}$ were dissolved in binding buffer to give a final concentration of $20 \mathrm{mg} \mathrm{mL}^{-1}$ and $1 \mathrm{mg}$ of DOX in PBS $(0.1 \mathrm{M}$, $\mathrm{pH}$ 7.2) was added to give a final concentration of $5 \mathrm{mg} \mathrm{mL}^{-1}$ in two $2 \mathrm{~mL}$ centrifuge tubes. After adding $100 \mu \mathrm{L}$ of conjugating reagent $\mathrm{A}$ and $120 \mu \mathrm{L}$ of conjugating reagent $\mathrm{B}$ to the $\mathrm{KLH}$ solution, we uniformly mixed and rotated the mixture for $30 \mathrm{~min}$ at RT for activation of the carboxyl groups. The activated protein solution was centrifuged at $14000 \mathrm{rpm}$ for $20 \mathrm{~min}$ at $4{ }^{\circ} \mathrm{C}$, and the supernatant was collected, dialyzed and concentrated to $50 \mathrm{mg} \mathrm{mL}^{-1}$. DOX solution was subsequently added to the collected solution, and the mixture was gently rotated overnight at RT and dialyzed against PBS (0.01 M, pH 7.2) for $48 \mathrm{~h}$. Competitive antigens were designed to use OVA or HSA as a carrier protein and were prepared using a similar method. A graphic illustration of the coupling procedure is shown in Fig. 1A. The conjugated immunogen and competitive antigen were identified by SDS-PAGE and ultraviolet-visible spectroscopy (UV-VIS), then lyophilized and stored at $-20{ }^{\circ} \mathrm{C}$ in the dark before use.

\subsection{Preparation of anti-doxorubicin antibody}

Six 6 week-old female BALB/c mice were subcutaneously immunized with $200 \mu \mathrm{g}$ of DOX-KLH conjugate in Freund's complete adjuvant. Immunization was repeated with the same dose two further times for reinforcement at 3 week intervals. The previously prepared DOX-OVA conjugated antigen was coated in 96-well plates with $600 \mathrm{ng}$ per well in coating buffer at $4{ }^{\circ} \mathrm{C}$ overnight, then blocked with gelatin blocking buffer at $4{ }^{\circ} \mathrm{C}$ overnight, lyophilized and stored at $4{ }^{\circ} \mathrm{C}$ before use. The titer of anti-DOX serum was tested using ELISA in series dilutions along with a negative control and a blank control. The antibody was then obtained from positive serum and purified using saturated ammonium sulfate precipitation and filtration chromatography and stored at $-20{ }^{\circ} \mathrm{C}$ for further use.

\subsection{Synthesis of SA-MPs}

Streptavidin-modified microparticles (SA-MPs) were synthesized by optimization of a previously reported technique (Fig. 1B). ${ }^{23}$ The carboxyl-modified MPs (CmMPs) were washed five times with binding buffer before activation of the carboxyl groups. $50 \mu \mathrm{L}$ of fresh conjugating reagent $\mathrm{A}$ and $80 \mu \mathrm{L}$ of conjugating reagent $\mathrm{B}$ were then added to a suspension of $10 \mathrm{mg}$ of CmMPs, with a concentration of $100 \mathrm{mg} \mathrm{mL}^{-1}(10.0 \times$ $10^{9} \mathrm{~mL}^{-1}$ in sterilized water) in a total volume of $1 \mathrm{~mL}$ of binding buffer, and rotated end-over-end for $30 \mathrm{~min}$ at RT. Activated CmMPs were then removed from the magnetic field and washed three times to remove excess reagents. Subsequently, $500 \mu \mathrm{g}$ of purified streptavidin in $1 \mathrm{~mL}$ binding buffer was added to the activated CmMPs and vertically mixed, gently rotating overnight at $25^{\circ} \mathrm{C}$. After washing three times with stock buffer to remove excess, the SA-MPs were blocked with stock buffer for $2 \mathrm{~h}$ at RT, then stored in the same solution at $4{ }^{\circ} \mathrm{C}$ until use.

\subsection{Biotinylation of antibody}

The biotinylation was carried out according to the product instructions for sulfo-NHS-LC-Biotin. $500 \mu \mathrm{g}$ of anti-DOX 
A

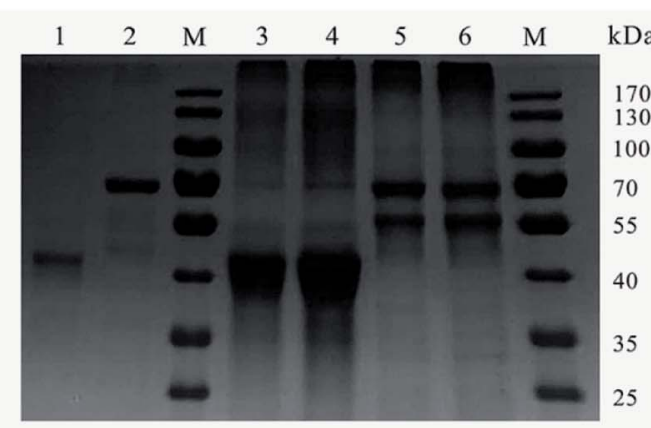

C

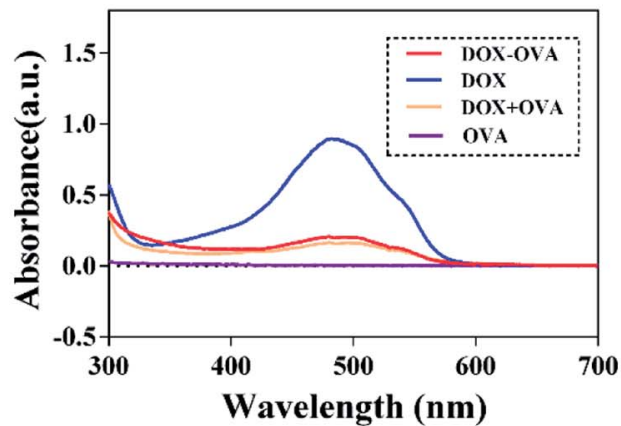

B

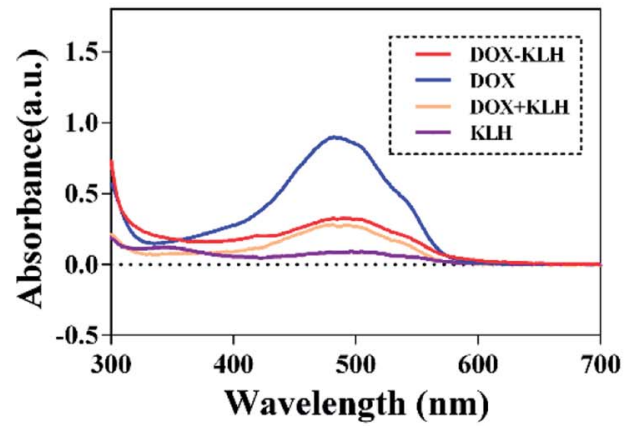

D

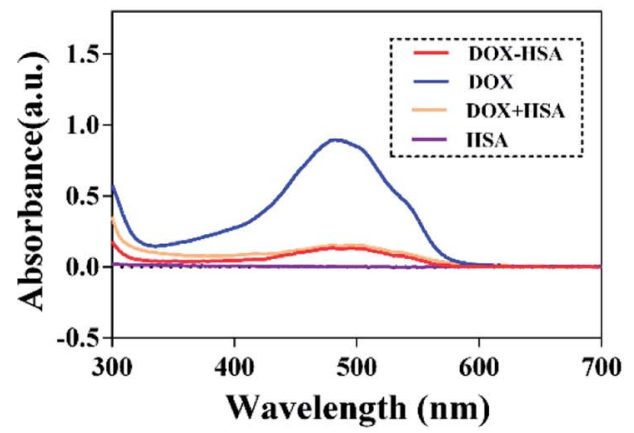

Fig. 3 Identification of synthetic antigens of DOX. (A) SDS-PAGE: line 1: blank OVA. Line 2: blank HSA. Line 3-4: DOX-OVA conjugate diluted with PBS at a ratio of $1 / 10$ and $1 / 5$, respectively. Line 5-6: DOX-HSA conjugate diluted with PBS at a ratio of $1 / 10$ and $1 / 5$, respectively. M: standard protein marker. $M_{\mathrm{w}}=$ molecular weight. OVA $=43 \mathrm{kD}, \mathrm{HSA}=67 \mathrm{kD}$. The UV-VIS spectra of three DOX-protein conjugates, including immunogen DOX-KLH conjugate (B), coating antigen DOX-OVA conjugate (C) and DOX-HSA conjugate (D). Blank control: unlinked carrier protein. Positive control: DOX in PBS. DOX-spiked unlinked carrier protein was all diluted in PBS.

polyclonal antibody previously acquired from antiserum, was added to 25-fold molar excess of sulfo-NHS-LC-Biotin solution in a total volume of $0.5 \mathrm{~mL}$, and the mixture was gently mixed for $1 \mathrm{~h}$ in the dark at RT. After the reaction, the mixture was dialyzed to remove the excess sulfo-NHS-LC-Biotin. Both previous and subsequent buffer exchange was performed using a 50KD-ultrafiltration tube (Amicon Ultra-0.5, Millipore) by washing 6-8 times with PBS buffer (pH 7.4). The purified biotinylated antibody was added to $0.1 \%$ BSA and $0.1 \%$ sodium azide and stored at $4{ }^{\circ} \mathrm{C}$, away from light.

Table 1 ELISA identification of anti-DOX serum $(n=3)^{b}$

\begin{tabular}{lllllll}
\hline & \multicolumn{2}{l}{$\mathrm{OD}^{a}(450 \mathrm{~nm})$} & & & \\
\cline { 2 - 7 } Dilutions & $\mathrm{I}$ & $\mathrm{II}$ & $\mathrm{III}$ & $\mathrm{IV}$ & $\mathrm{V}$ & $\mathrm{VI}$ \\
\hline $1 / 1000$ & 3.021 & 2.677 & 1.699 & 2.899 & 1.811 & 2.567 \\
$1 / 2000$ & 2.425 & 1.344 & 0.924 & 1.674 & 1.021 & 1.429 \\
$1 / 4000$ & 1.875 & 0.782 & 0.482 & 1.033 & 0.622 & 0.986 \\
$1 / 8000$ & 0.877 & 0.53 & 0.202 & 0.577 & 0.321 & 0.603 \\
$1 / 16000$ & 0.325 & 0.238 & 0.182 & 0.312 & 0.233 & 0.344 \\
$1 / 32000$ & 0.193 & 0.199 & 0.191 & 0.206 & 0.197 & 0.188 \\
Negative control & 0.198 & 0.201 & 0.192 & 0.191 & 0.187 & 0.205 \\
Blank control & 0.051 & 0.049 & 0.053 & 0.05 & 0.058 & 0.047
\end{tabular}

${ }^{a}$ OD: optical density. ${ }^{b}$ I-VI: ID of BALB/c mice.

\subsection{Preparation of lanthanide-labeled competitive antigen}

The DOX-OVA conjugate was prepared as described in the previous section and used as the competitive antigen of DOX in this analytical method. Following an established approach for the synthesis of $\mathrm{Eu}^{3+}$ chelate-labeling, first, $500 \mu \mathrm{g}$ of purified DOX-OVA conjugate was redissolved in $200 \mu \mathrm{L}$ of labeling buffer. Ultrafiltration tubes (Amicon Ultra-0.5, $10 \mathrm{KD}$, Millipore) were then used to wash 6 times with labeling buffer while centrifuging at $9500 \mathrm{rpm}$ for $6 \mathrm{~min}$, the sample was recovered and centrifuged at $3000 \mathrm{rpm}$ for $3 \mathrm{~min}$ to collect the proteins after the last wash. $100 \mu \mathrm{g}$ of DTTA$\mathrm{Eu}^{3+}$ chelate was then added to the DOX-OVA conjugate solution. After complete mixing, the mixture was incubated

Table 2 Cross-reactivity of DOX related compounds

\begin{tabular}{lll}
\hline Compounds & $\mathrm{IC}_{50}{ }^{a}\left(\mathrm{ng} \mathrm{mL}^{-1}\right)$ & $\mathrm{CR}^{b}(\%)$ \\
\hline Epirubicin (EPI) & 899.5 & 97.7 \\
Daunorubicin (DAU) & 840.6 & 107.5 \\
5-Fluorouracil (5-FU) & $>200000$ & - \\
Paclitaxel (PTX) & $>200000$ & - \\
Docetaxel (DTX) & $>200000$ & - \\
Cisplatin (Pt) & $>200000$ & -
\end{tabular}

${ }^{a} \mathrm{IC}_{50}$ : half maximal inhibitory concentration. ${ }^{b}$ CR: cross-reactivity. 
A
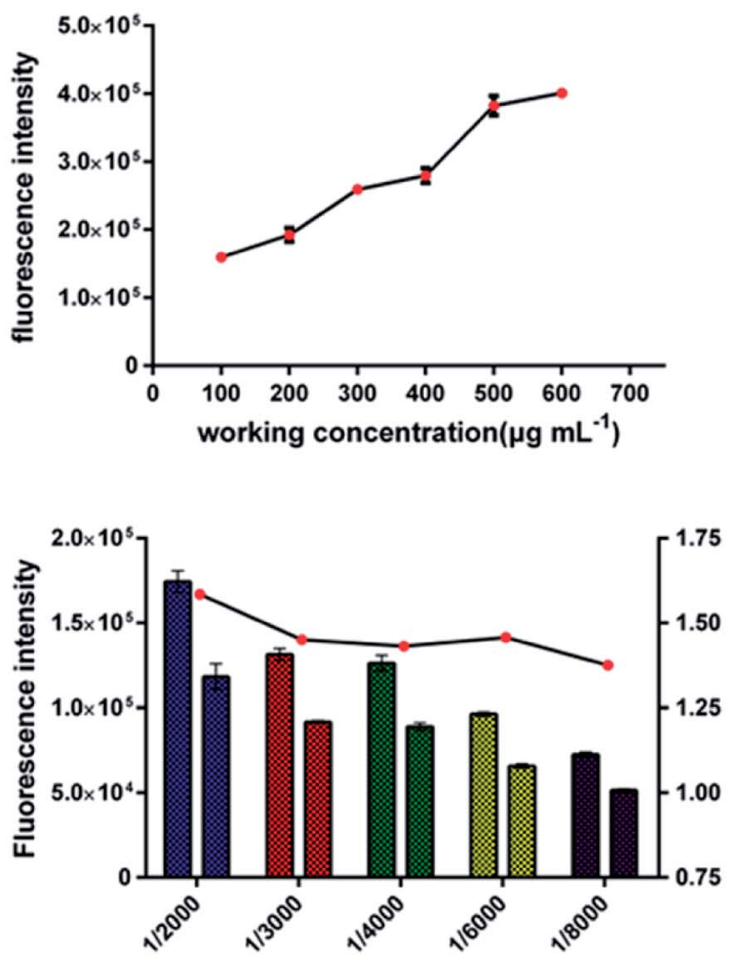

Dilution ratio of biotinylated antibody
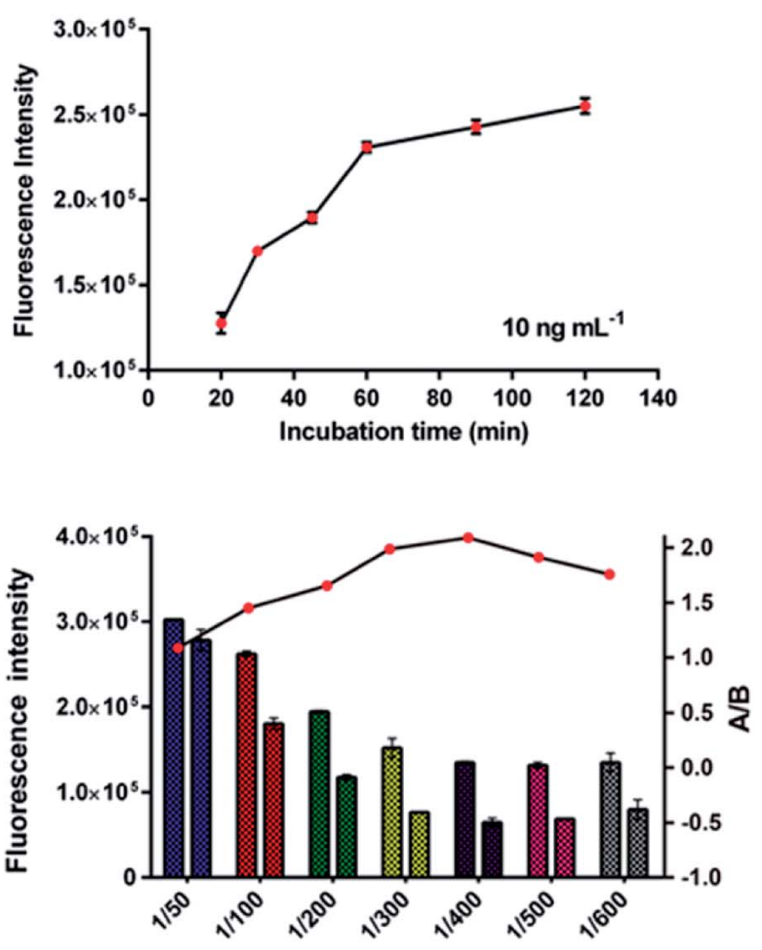

Dilution ratio of $\mathrm{Eu}^{3+}$-labeled antigen

Fig. 4 Optimum reaction conditions for SA-MP-based TRFIA in detection of doxorubicin. (A) Working concentration of the SA-MPs. (B) Incubation time. (C) Dilution ratio of biotinylated antibody. (D) Dilution ratio of $\mathrm{Eu}^{3+}$-labeled antigen.

gently for $18-20 \mathrm{~h}$ at RT away from light. On the following day, excess $\mathrm{Eu}^{3+}$-chelates were separated from the target labeled protein on a Sephadex G-50 column $(1.5 \mathrm{~cm} \times 40 \mathrm{~cm})$. The synthesized and purified $\mathrm{Eu}^{3+}$ labeled DOX-OVA antigens were kept stable for 12 months by adding $0.1 \%$ BSA as a stabilizer.

\subsection{Standard, quality control, and clinical serum samples}

DOX was dissolved in DI water at a concentration of $200 \mu \mathrm{g}$ $\mathrm{mL}^{-1}$ to give a working solution. DOX standards with seven concentrations were prepared by diluting the working solution with standard buffer to give standards with the following concentrations: $0,50,100,250,500,750,1500$, and $3000 \mathrm{ng}$ $\mathrm{mL}^{-1}$. Quality Control samples (QCs) were prepared in low, medium, and high concentrations, by spiking $10 \mathrm{~mL}$ of blank serum with DOX working solution to give final concentrations of 100,500 , and $1000 \mathrm{ng} \mathrm{mL}^{-1}$, respectively. Thirty-two clinical serum samples containing doxorubicin from cancer patients under adjuvant therapy were generously provided by Nan-fang Hospital (Guangzhou, China). Twenty cases of blank serum samples and blank urine samples from healthy volunteers were also collected and tested. Negative samples were then pooled as blank solvent to assess the matrix effect. Verbal informed consents were obtained by all participants.

\subsection{Assay procedures}

We performed this novel SA-MP-based TRFIA method using an indirect competitive inhibition method for determination of doxorubicin in human serum or urine. Schematic illustration of SA-MP-based TRFIA is provided in Fig. 1. Before the test, some preliminary treatments were carried out as follows: 96-well plates were blocked with blocking buffer containing 5\% BSA at $4{ }^{\circ} \mathrm{C}$ overnight, lyophilized the following day and stored at $4{ }^{\circ} \mathrm{C}$ until use. SA-MPs were diluted with stock solution to a concentration of $500 \mu \mathrm{g} \mathrm{mL} \mathrm{m}^{-1}$ as a working solution. In the determination of DOX concentration, homogenic SA-MPs were added to the blocked 96-well plate, $25 \mu \mathrm{L}$ per well, followed by biotinylated anti-DOX antibody diluted solution, $50 \mu \mathrm{L}$ per well, at a dilution ratio of $1 / 2000$ for serum samples and $1 / 4000$ for calibrations. A series of standards or test samples were then added, $25 \mu \mathrm{L}$ per well. Finally, $\mathrm{Eu}^{3+}$ labeled DOX-HSA was diluted to a ratio of $1 / 400$ and the diluted solution was added (50 $\mu \mathrm{L}$ per well). Then the mixture was incubated under vibration at $37^{\circ} \mathrm{C}$ for $1 \mathrm{~h}$. During the process of detection, all dilutions were prepared with assay buffer. The assay was carried out in triplicate.

\subsection{Validation of the proposed model}

The mean and standard deviations (SD) of the fluorescence measurements were calculated at the zero point $\left(0 \mathrm{ng} \mathrm{mL}{ }^{-1}\right)$ on 
A

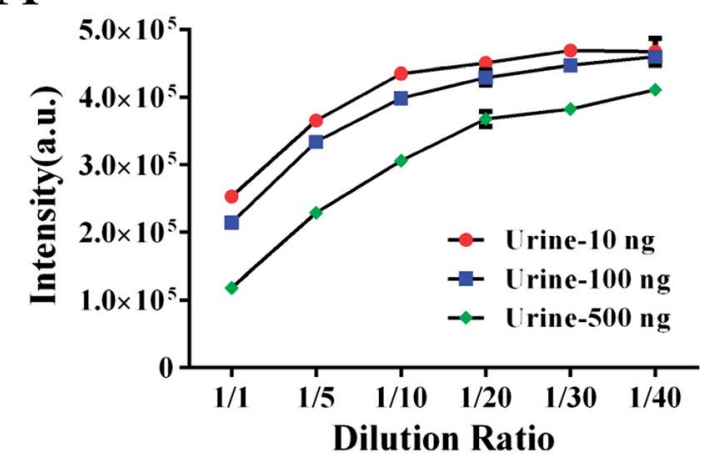

C

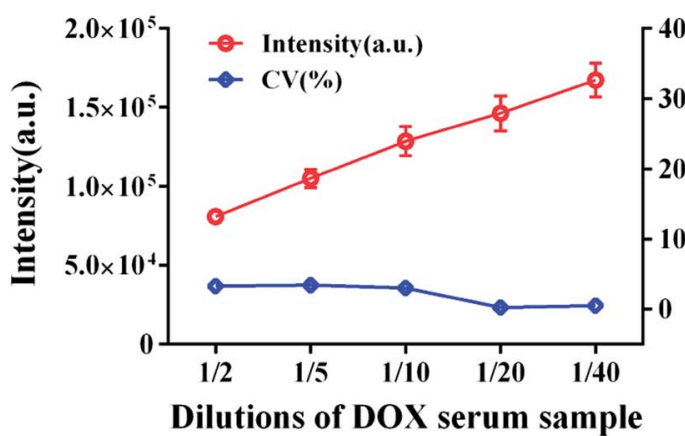

$\mathrm{B}$

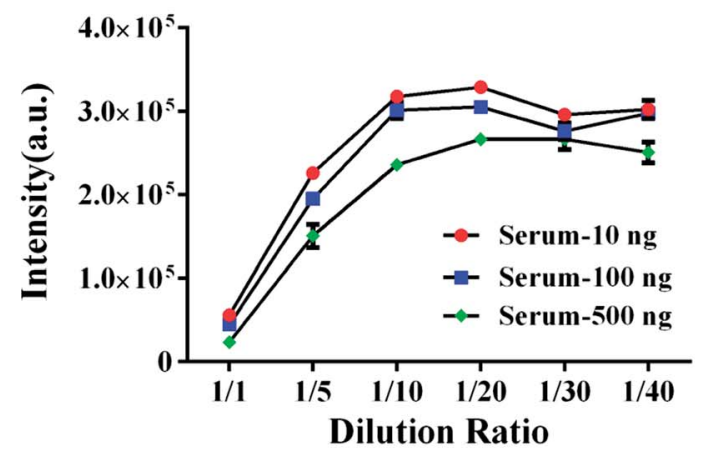

D

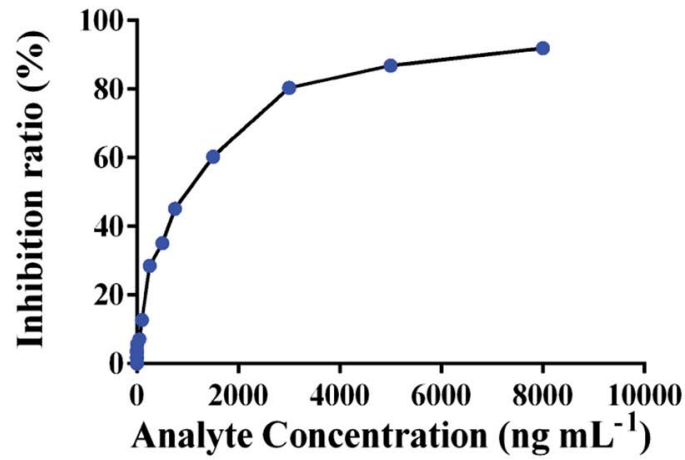

Fig. 5 Dilutions and inhibition curve of DOX. (A) Dilution curve of spiked urine samples. (B) Dilution curve of spiked serum samples. (C) Dilution curve of actual clinical serum sample. (D) Inhibition curve of free DOX with the $1 C_{50}$ of $903.9 \mathrm{ng} \mathrm{mL}^{-1}$.

the standard curves for 10 duplicates. Sensitivity was calculated as the concentration corresponding to the value of mean $-2 \times$ $\mathrm{SD}$, as determined via the standard curve. After determining the background response produced by nonspecific binding by the SA-MP-based TRFIA method, three spiked amounts of DOX $(100,500$, and $1000 \mathrm{ng})$ were added to the known samples (25.2, 516.5 , and $1020.1 \mathrm{ng} \mathrm{mL}^{-1}$ ), and the recovery was calculated as the ratio of each observed value to its expected value $((\mathrm{OV} / \mathrm{EV}) \times$ $100 \%)$. The intra- and inter-assay precisions were determined from measurements obtained by analyzing three QC samples including low (QC-1, $100 \mathrm{ng} \mathrm{mL}^{-1}$ ), medium (QC-2, $500 \mathrm{ng}$ $\left.\mathrm{mL}^{-1}\right)$ and high (QC-3, $1000 \mathrm{ng} \mathrm{mL}^{-1}$ ) concentration. This assay was carried out ten times for the intra-assay and in triplicate for the inter-assay. Analogues that are structurally related to DOX, including epirubicin (EPI) and daunorubicin (DAU), were tested for cross-reactivity. In this case, other anticancer drugs subsequently used or used in combination including 5 -fluorouracil (5-FU), paclitaxel (PTX), docetaxel (DTX) and cisplatin (Pt) were also tested.

\subsection{Statistics}

Data analysis was performed using Statistical Product and Service Solutions (SPSS) software (version 20.0, SPSS Inc., Chicago, IL). A two-tailed test was applied for statistical analysis in all tests with alpha level set at $\alpha=0.05$. A $P$ value of less than $5 \%$ $(P<0.05)$ was considered statistically significant. The dose- response curve under double-logarithm fit using Origin Pro7.5 (GE, Piscataway, NJ, USA) was $\log (Y)=B+A \times \log (X)$, specifically, $\log (Y)=\left[\left(B / B_{0}\right) /\left(1-B / B_{0}\right)\right]$, where $B$ is the corresponding fluorescence value (FV), $B_{0}$ is the $\mathrm{FV}$ of the zero-point, and $X$ is the concentration of DOX in the test samples.

\subsection{LC-MS/MS procedure}

The LC-MS/MS method was based on several previous reports ${ }^{16,30,31}$ with slight adjustments, using DAU as an internal standard (IS). The working solution was diluted into working standards $\left(0,1,10,50,100,500\right.$, and $\left.1000 \mathrm{ng} \mathrm{mL}^{-1}\right)$. Each standard sample was spiked with IS to give a final concentration of $200 \mathrm{ng} \mathrm{mL}^{-1}$. An extraction procedure previously shown to have satisfactory recovery, was used to extract DOX from the serum samples ${ }^{15}$ (see details in ESI $\dagger$ ). Mass analysis was performed on API 3200 triple quadrupole tandem mass spectrometers following HPLC separation. The results were analyzed by ABI Analyst ${ }^{\circledR}$ Software.

\section{Results}

\subsection{Identification of synthetic antigens}

The fluorescence characteristics and UV-VIS spectrum of doxorubicin are shown in Fig. 2 and its molecular structure is shown in Fig. 1D. The maximum absorption of DOX is at $495 \mathrm{~nm}$ and the excitation and emission wavelengths were at 495 and 
$595 \mathrm{~nm}$, respectively. The purified DOX-conjugated antigens were identified by SDS-PAGE (Fig. 3A) and UV-VIS spectroscopy (Fig. 3B-D) using blank carrier proteins as a blank control, which indicated a satisfactory coupling. Because the DOX-KLH conjugate was too large to run SDS-PAGE and MALDI-TOF MS, it was fully purified by dialysis and characterized by UV-VIS spectroscopy, identifying the characteristic UV absorption of DOX. Both the DOX-OVA conjugate and DOX-HSA conjugate were presented with two protein bands, with one band in line with the corresponding blank carrier protein and the other one below the blank carrier protein, indicating the existence of both linked product and unlinked carrier protein. This result indicated that the conjugation of tens of DOX molecules might alter the hydrophobicity of the surface and interfere with the surfacecharges of the protein complex, speeding up their electrophoretic rate. UV-VIS spectroscopy of all three drug-conjugated proteins showed that the protein complexes gained the characteristic absorption peak of DOX at $495 \mathrm{~nm}$. Unlinked protein carriers set as blank controls showed no absorbance at $495 \mathrm{~nm}$. The molar coupling ratio of DOX/carrier protein was calculated with the following formula (Conc. is an abbreviation of concentration)

Coupling ratio $=$

Conc. of doxorubicin $(\mathrm{A} 495) \times M_{\mathrm{w}}$ of carrier protein $\overline{M_{\mathrm{w}} \text { of doxorubicin } \times \text { Conc. of carrier protein (A562) }}$

The molar coupling ratio of DOX/KLH was calculated to be $1 /$ 42. The molar coupling ratios of DOX/OVA and DOX/HSA were $1 / 10$ and $1 / 12$, respectively.

\subsection{Identification of antibody}

The titer of anti-DOX serum was tested by ELISA (Table 1) and the serum of mouse I was purified for further use. We found the anti-DOX antibody prepared had high cross-reactivity (CR) to its isomer, EPI, and other anthracyclines, and little CR to other common combination drugs (Table 2). The CR to EPI was $97.7 \%$

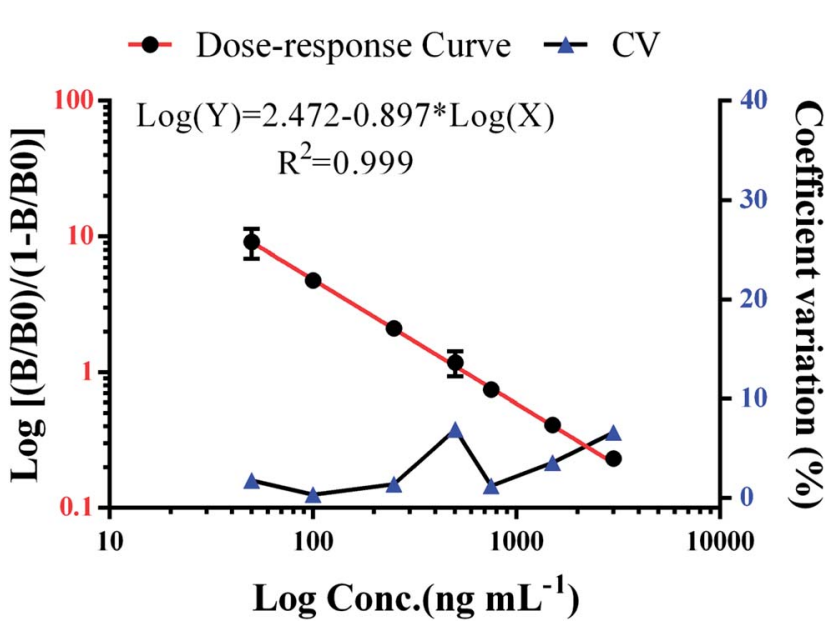

Fig. 6 Dose-response curve of spiked standard samples. with an $\mathrm{IC}_{50}$ of $899.5 \mathrm{ng} \mathrm{mL} \mathrm{m}^{-1}$ and the $\mathrm{CR}$ to DAU was $107.5 \%$

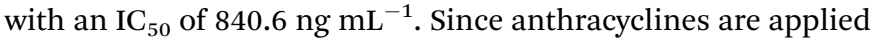
singly in clinical use, the detection of DOX would not be affected by its CR with other anthracyclines. For better analytical performance and specificity, we would screen monoclonal antibody, which is specific to DOX, and scale-up the preparation.

\subsection{Optimization experiments}

The coupling ratio of SA was calculated to be $67 \%$ according to the following formula:

Coupling ratio $=\left(\left(\right.\right.$ supernatant protein concentration $\left.\left(\mu \mathrm{g} \mathrm{mL}^{-1}\right)\right)$ $\times$ volume $(\mathrm{mL}) / 500) \times 100 \%$

The optimum reaction conditions for the proposed SA-MPbased TRFIA method for determination of DOX in human samples were investigated to optimize performance. In this case, we devised several experiments to find the most suitable reaction conditions, including working concentration of SAMPs applied, incubation time, and dilution ratio of biotinylated anti-DOX antibody and $\mathrm{Eu}^{3+}$-labeled competitive antigen. All optimum reaction conditions were chosen based on appropriate fluorescence value (FV) and the highest FV ratio of $A / B\left(A-250 \mathrm{ng} \mathrm{mL}{ }^{-1}, B-1500 \mathrm{ng} \mathrm{mL}^{-1}\right)$. To ensure the sensitivity, a low concentration of DOX standard sample (QC-1, 100 $\mathrm{ng} \mathrm{mL}^{-1}$ ) and excess biotinylated anti-DOX antibody and $\mathrm{Eu}^{3+}$. labeled antigen, were applied in a two-step reaction. The reaction volume of SA-MPs was fixed at $25 \mu \mathrm{L}$. The sensitivity was investigated with working concentrations of SA-MPs (100, 200, $300,400,500$, and $600 \mu \mathrm{g} \mathrm{mL}^{-1}$ ) and tested following incubation for $60 \mathrm{~min}$, and the results are shown in Fig. 4A, indicating that the best working concentration of SA-MPs was $500 \mu \mathrm{g} \mathrm{mL}^{-1}$. The assay was tested at different incubation time points using 500 $\mu \mathrm{g} \mathrm{mL}^{-1}$ SA-MPs as a working concentration with excess antibody and $\mathrm{Eu}^{3+}$-labeled antigen in a one-step reaction. The results showed that the optimum incubation time was $60 \mathrm{~min}$ (Fig. 4B). The optimum dilution ratio of biotinylated anti-DOX antibody and $\mathrm{Eu}^{3+}$-labeled antigen were also investigated using a series of diluted spiked serum samples. The results were plotted as a multiple bar chart (Fig. 4C and D) and the optimum dilution ratios of biotinylated anti-DOX antibody and $\mathrm{Eu}^{3+}$ labeled antigen for serum samples were found to be $1 / 2000$ and $1 / 400$, respectively.

\subsection{Dilution curve and matrix effect}

The suitable dilution ratio of DOX-spiked urine or serum samples was investigated (Fig. 5A and B). Based on the dilution curve, dilutions from $1 / 5$ to $1 / 10$ were a suitable choice for good stability and a reduced matrix effect. To avoid the interference of the matrix effect, the dilution ratio of biotinylated anti-DOX antibody for calibration standards in standard buffer was also investigated by comparing the intensity of standards in spiked serum samples. The dilutions of antibody were $1 / 2000$ in serum samples and 1/4000 in standard buffer. However, the matrix 
Table 3 Precision of SA-MP-based TRFIA ${ }^{a}$

\begin{tabular}{|c|c|c|c|c|}
\hline & Samples & Concentration $\left(\mathrm{ng} \mathrm{mL} \mathrm{m}^{-1}\right)$ & Mean $\pm \mathrm{SD}\left(\mathrm{ng} \mathrm{mL}^{-1}\right)$ & $\mathrm{CV}(\%)$ \\
\hline \multirow[t]{2}{*}{ Intra-assay $\left({ }^{*} 10\right)$} & QC-1 & 100 & $99.80 \pm 4.11$ & 4.12 \\
\hline & QC-2 & 500 & $507.08 \pm 28.59$ & 5.63 \\
\hline \multirow[t]{3}{*}{ Inter-assay $\left({ }^{*} 5\right)$} & QC-1 & 100 & $106.40 \pm 7.35$ & 6.91 \\
\hline & QC-2 & 500 & $512.82 \pm 28.10$ & 5.48 \\
\hline & QC-3 & 1000 & $984.64 \pm 64.17$ & 6.51 \\
\hline
\end{tabular}

${ }^{a} \mathrm{CV}$ : coefficient variation.

effect in urine samples remains an unsolved problem for large variations in detection, the elimination of which requires further investigation.

\subsection{Analytical performance}

We have demonstrated a novel analytical method, which is rapid, applicable, and was successfully validated using clinical serum samples. The presented method combines the convenience and efficiency of captured carrier SA-MPs and the benefits of a time-resolved fluorescence immunoassay. The analytical performance of the SA-MP-based TRFIA was demonstrated by a wide detection range, ultra-sensitivity, and satisfactory precision and recovery. Actual clinical serum samples containing DOX were diluted from $1 / 2$ to $1 / 40$ and the dilution curve in Fig. 5C shows satisfactory linearity and little variation. The inhibition curve of free DOX is shown in Fig. 5D with an $\mathrm{IC}_{50}$ value of $903.9 \mathrm{ng} \mathrm{mL}^{-1}$. Dose-response curve of spiked standard samples is given in Fig. 6 with an $R^{2}$ value of 0.999 . The analytical sensitivity of this proposed method was $3.8 \mathrm{ng} \mathrm{mL}$ and the linear range of detection was from 3.8 to $3000 \mathrm{ng} \mathrm{mL}{ }^{-1}$, which covers the quantification requirements of routine drug monitoring. The intra- and inter-assay coefficients of variation were $4.12-5.72 \%$ and $5.48-6.91 \%$, respectively (Table 3 ). The recovery was from $94.3 \%$ to $108.3 \%$ (Table 4 ). The performance of the proposed method satisfied the reagent requirements.

Table 4 Recovery of SA-MP-based TRFIA

\begin{tabular}{lllll}
\hline Samples & Spiked & \multicolumn{2}{l}{ Value $\left(\mathrm{ng} \mathrm{mL} \mathrm{m}^{-1}\right)$} & \\
$\left(\mathrm{ng} \mathrm{mL} \mathrm{m}^{-1}\right)$ & DOX (ng) & Expected & Observed & Recovery (\%) \\
\hline
\end{tabular}

\section{Sample A}

25.2

$\begin{array}{llll}100 & 125.2 & 131.6 & 105.1 \\ 500 & 525.2 & 495.3 & 94.3 \\ 1000 & 1025.2 & 1064.7 & 103.8\end{array}$

\section{Sample B} 516.5

$\begin{array}{llll}100 & 616.5 & 582.1 & 94.4 \\ 500 & 1016.5 & 1057.5 & 104 \\ 1000 & 1516.5 & 1476.3 & 97.3\end{array}$

Sample C

$\begin{array}{lllll}320.1 & 100 & 420.1 & 453.9 & 108 \\ & 500 & 820.1 & 780.5 & 95.1 \\ & 1000 & 1320.1 & 1367.4 & 103.5\end{array}$

\subsection{Comparison with LC-MS/MS assay}

Clinical serum samples were analyzed using SA-MP-based TRFIA and LC-MS/MS simultaneously. All data were plotted and the correlation between the concentrations detected by the two methods is presented in Fig. 7. The peak for the quantified ion of calibration with $\mathrm{m} / \mathrm{z}$ value of 361.30 is given in Fig. 7A, and the peak of the IS product ion is also given with an $\mathrm{m} / \mathrm{z}$ value of 321.30 (Table 5). The LC-MS/MS calibration curve is presented in Fig. 7B, with the ratio of analyte peak area/IS peak area on the $y$-axis and the analyte concentration on the $x$-axis with an $R^{2}$ value of 0.9999 . The linear correlation between the two methods was good $\left(R^{2}=0.9868\right.$, Fig. $\left.7 \mathrm{C}\right)$. The results indicated the SA-MP-based TRFIA has satisfactory analytical performance and is comparable with the LC-MS/MS method for determination of DOX concentration in human serum samples. However, the application in urine samples was limited by fluctuations in the acidity or alkalinity causing large variations during the assay. It is possible that this $\mathrm{pH}$ interference could be attenuated by sample dilution, however this requires further investigation for confirmation.

\section{Discussion}

Many of the available analytical methods capable of high sensitivity have other disadvantages making them inappropriate for use in routine TDM. Currently, mass spectrometry remains the most reliable and precise analytical method for quantification of chemicals in many fields. However, LC-MS/MS is still used mostly in scientific research and its application in clinical testing is limited by its involved sample treatment. It also requires demanding technical training and expensive equipment, which impedes its application in fundamental hospitals. In contrast, magnetic microparticle-based immunoassays are simple and can be easily developed into an automated detection platform, thereby bringing significant convenience to routine practice and limiting the variability resulting from manual operation in a clinical laboratory. There are several immunoassays based on enzyme-linked immunosorbent assay (ELISA) or immune turbidimetry being used in detection of anticancer drugs, which are well-developed but time-consuming, and have short detection range, insufficient precision, and unsatisfactory analytical sensitivity. ${ }^{32}$ Compared with ELISA, TRFIA has clear advantages such as a wide detection range and high sensitivity. ${ }^{33}$ Many pharmacokinetics reports 
A
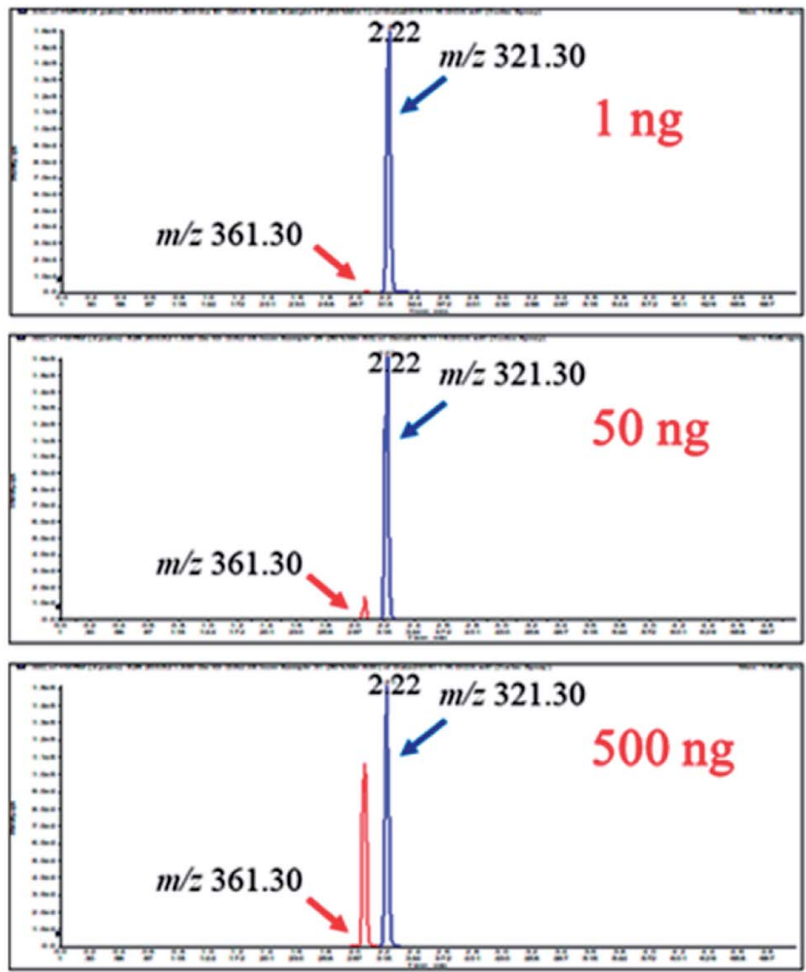

B

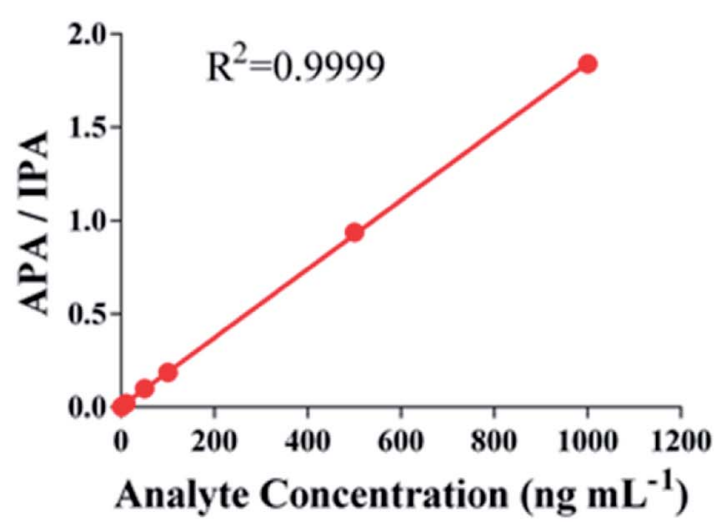

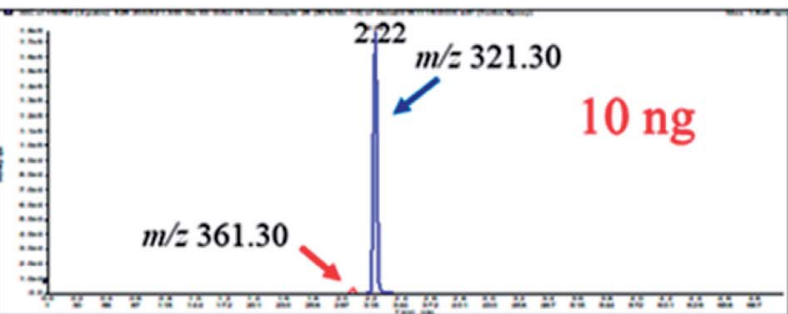
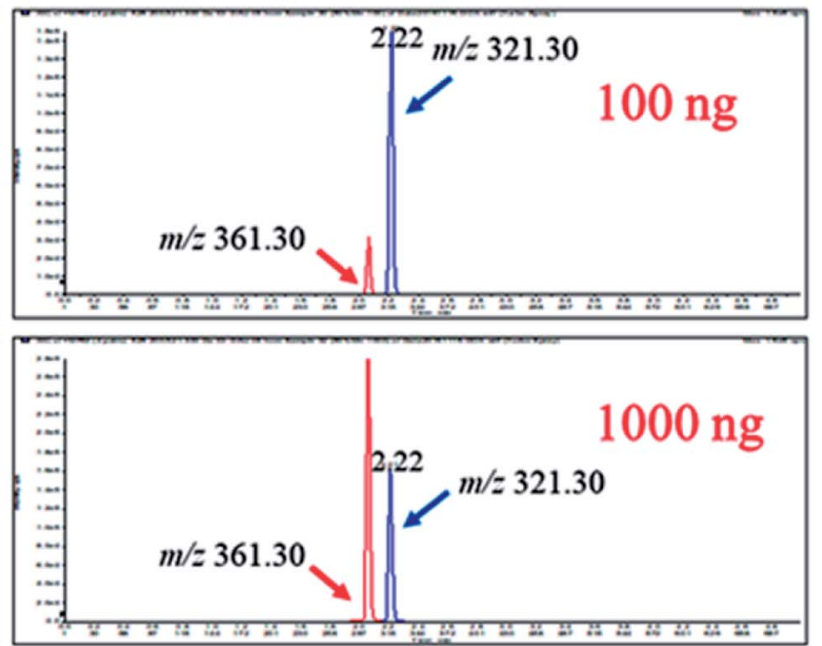

C

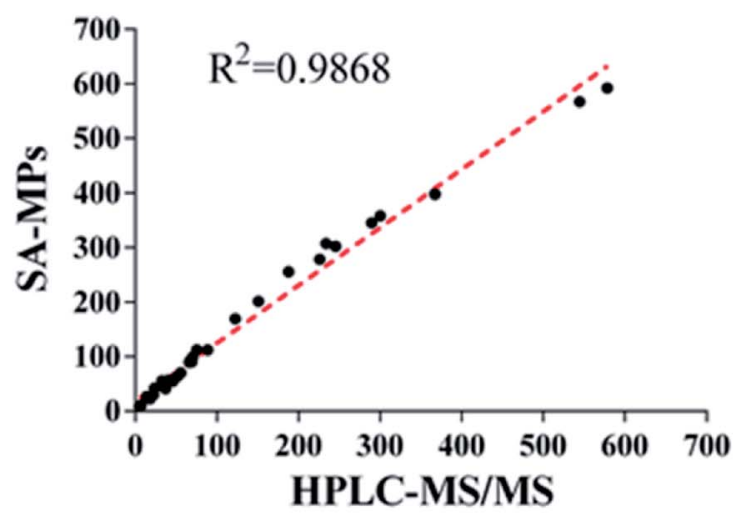

Fig. 7 LC-MS/MS analysis and comparison with SA-MP-based TRFIA. (A) LC-MS/MS analysis of the following DOX standards: 1, 10, 50, 100, 500, and $1000 \mathrm{ng} \mathrm{mL}^{-1}$. Quantitative index: $\mathrm{m} / \mathrm{z}$ 361.30, fragment of DAU: $\mathrm{m} / \mathrm{z}$ 321.30. (B) LC-MS/MS calibration curve of DOX. APA $=$ analyte peak area, IPA = IS peak area. (C) Linear correlation between the proposed SA-MP-based TRFIA and LC-MS/MS $\left(R^{2}=0.9868\right)$.

indicate that the concentration of DOX after infusion could be $1000 \mathrm{ng} \mathrm{mL}^{-1}$ or even higher, ${ }^{34-37}$ which challenges the applicability of ELISA. Pleasingly, the developed SA-MP-based TRFIA is a refinement of traditional TRFIA ${ }^{23}$ and presents excellent performance in detection of DOX. In this study, the large determination range of target drug possible with the analytical

Table 5 Molecular masses and product ions ${ }^{a}$

\begin{tabular}{lll}
\hline Compounds & Doxorubicin & Daunorubicin \\
\hline Mass & 544 & 528 \\
Product ion & $361^{\mathrm{a}}$ & 321 \\
& $397^{\mathrm{b}}$ &
\end{tabular}

${ }^{a} \mathrm{a}-$ Quantified ion, $\mathrm{b}$ - qualified ion. method, satisfies the demand of quantifying all target concentrations. Electrochemical immunoassay is also referenced as its high sensitivity and simple equipment. Many modified electrochemical immunoassays using different labels such as $[\mathrm{Ru}(\mathrm{bpy}) 3]^{3+},{ }^{38,39}$ gold nanoparticles (AuNPs) $)^{40,41}$ and quantum $\operatorname{dots}^{\mathbf{4 2}}$ or label-free electrochemical immunosensor ${ }^{\mathbf{4 3 , 4 4}}$ have been developed at the research level. However, it is not likely to be performed multiple labelling which limits the use of simultaneous detection of multiple biomarkers. In this aspect, our developed SA-MP-based TRFIA can be further applied in simultaneous detections.

By virtue of its simplicity and excellent analytical performance, this developed analytical method could be used for realtime drug monitoring in the clinic to reduce the burden on 
clinical workers and the harm caused by unnecessary dosing of cancer patients. With facile screening, doses can be adjusted accordingly to keep the concentration within the target range through real-time monitoring of the drug concentration in targeted biological fluids, and estimating specific drug metabolism and tolerance in individuals in specific situations. This could contribute to the optimization and expansion of precision medicine in chemotherapy, which has significant promise for future application.

As a simple and automated analytical technology, our developed SA-MP-based TRFIA is expected to help in achieving the popularization of TDM because we can provide objective reference data for clinical practitioners to rapidly make individual dosage adjustments for patients. These useful data can also assist medical staff in analyzing individual pharmacokinetic differences among groups with different traits based on gender, age, somatotype, and even genotype. However, there remain many reasons why TDM has not been fully implemented in daily clinical practice. Primarily these involve the challenge of establishing the safe range of appropriate target drug concentration and therapeutic indices for different populations, and the combination strategies of multiple drugs in clinical use, which further increases the complexity in the refinement of guidelines.

To address the former, we have developed an efficient analytical method for TDM of anticancer drugs. Based on this novel analytical method, we envision a blueprint to clarify the individual factors, both at the genetic level and overall physical level, that play an important role in the metabolism of anticancer drugs, by collecting and analyzing more clinical data and metabolic differences. We would then help to establish a general TDM guideline for further application to achieve precision personalized medicine.

Moreover, since many chemotherapy drugs are co-used in treatment, it would be possible for us to further develop a reagent for simultaneous determination of two drugs or simultaneous monitoring of one particular drug and its relevant biomarkers, reflecting the toxicity caused by this drug. Duallabeling has been applied in various fields and is convenient for the detection of multiple biomarkers in in vitro diagnostics. Europium chelate is the most frequently used label in TRFIA, followed by samarium chelate and terbium chelate. By using different labels such as europium chelate and samarium chelate that have advantages such as narrow emission spectra and lack of fluorescence spectra overlap between one another, we would be able to devise ultrasensitive simultaneous determination.

\section{Conclusions}

In this study, we have developed a simple, rapid, and ultrasensitive analytical method that was applied in the field of TDM for anticancer drugs. Using the example of DOX, we have successfully developed an effective analytical method for realtime TDM of anticancer drugs in human biological fluids, via the combination of versatile easily separated SA-MPs and the demonstrated consistency of time-resolved fluorescence immunoassay. This analytical method has significant potential in the application of future TDM. The extension of the assay to the simultaneous detection of multiple drug combinations or monitor-required biomarkers is currently under investigation.

\section{Conflicts of interest}

None.

\section{Abbreviations}

$\begin{array}{ll}\text { TDM } & \text { Therapeutic drug monitoring } \\ \text { DOX } & \text { Doxorubicin hydrochloride } \\ \text { CmMPs } & \text { Carboxyl-modified magnetic microparticles } \\ \text { SA-MPs } & \text { Streptavidin-modified magnetic microparticles } \\ \text { TRFIA } & \text { Time-resolved fluorescence immunoassay } \\ \text { BSAS } & \text { Biotin-streptavidin system } \\ \text { LC-MS/ } & \text { Liquid chromatography tandem mass spectrometry } \\ \text { MS } & \\ \text { MES } & \text { 4-Morpholineethanesulfonic acid } \\ \text { Sulfo- } & \text { N-Hydroxysulfosuccinimide } \\ \text { NHS } & \\ \text { EDC } & \text { 1-Ethyl-3-(3-dimethylaminopropyl) carbodiimide } \\ & \text { hydrochloride } \\ \text { KLH } & \text { Keyhole limpet hemocyanin } \\ \text { HSA } & \text { Human serum albumin } \\ \text { SA } & \text { Streptavidin } \\ \text { OVA } & \text { Ovalbumin } \\ \text { BSA } & \text { Bovine serum albumin } \\ \text { RT } & \text { Room temperature }\end{array}$

\section{Acknowledgements}

The authors are grateful to the support of The National Natural Science Foundation of China [Grant No. 81702072 and No. 21575058] and China Postdoctoral Science Foundation [Grant No. 2016M600662].

\section{References}

1 W. Chen, R. Zheng, P. D. Baade, S. Zhang, H. Zeng, F. Bray, A. Jemal, X. Q. Yu and J. He, CA: Cancer J. Clin, 2016, 66, 115132.

2 R. L. Siegel, K. D. Miller and A. Jemal, Ca-Cancer J. Clin., 2016, 66, 7-30.

3 A. J. Galpin and W. E. Evans, Clin. Chem., 1993, 39, 24192430.

4 M. J. Moore and C. Erlichman, Clin. Pharmacokinet., 1987, 13, 205-227.

5 T. Tangden, V. Ramos Martin, T. W. Felton, E. I. Nielsen, S. Marchand, R. J. Bruggemann, J. B. Bulitta, M. Bassetti, U. Theuretzbacher, B. T. Tsuji, D. W. Wareham, L. E. Friberg, J. J. De Waele, V. H. Tam, J. A. Roberts, t. P. Infection Section for the European Society of Intensive Care Medicine, M. Pharmacodynamics Study Group of the European Society of Clinical, t. I. S. o. A.-I. P. Infectious 
Diseases and M. the Critically Ill Patients Study Group of European Society of Clinical and D. Infectious, Intensive Care Med., 2017, 43, 1021-1032.

6 S. C. van Dijkman, S. G. Wicha, M. Danhof and O. E. Della Pasqua, Clin. Pharmacol. Ther., 2018, 103, 663-673.

7 J. W. Newcomer and M. J. Sernyak, J. Clin. Psychiatry, 2007, 68, e17.

8 N. Widmer, C. Bardin, E. Chatelut, A. Paci, J. Beijnen, D. Levêque, G. Veal and A. Astier, Eur. J. Cancer, 2014, 50, 2020-2036.

9 Y. Y. Hon and W. E. Evans, Clin. Chem., 1998, 44, 388-400.

10 A. Paci, G. Veal, C. Bardin, D. Levêque, N. Widmer, J. Beijnen, A. Astier and E. Chatelut, Eur. J. Cancer, 2014, 50, 2010-2019.

11 S. C. Piscitelli, K. A. Rodvold, D. A. Rushing and D. A. Tewksbury, Clin. Pharmacol. Ther., 1993, 53, 555-561.

12 B. E. Levis, P. F. Binkley and C. L. Shapiro, Lancet Oncol., 2017, 18, e445-e456.

13 B. Gao, S. Yeap, A. Clements, B. Balakrishnar, M. Wong and H. Gurney, J. Clin. Oncol., 2012, 30, 4017-4025.

14 A. Rousseau and P. Marquet, Fundam. Clin. Pharmacol., 2002, 16, 253-262.

15 S. R. Urva, B. S. Shin, V. C. Yang and J. P. Balthasar, J. Chromatogr. B: Anal. Technol. Biomed. Life Sci., 2009, 877, 837-841.

16 S. Ibsen, Y. Su, J. Norton, E. Zahavy, T. Hayashi, S. Adams, W. Wrasidlo and S. Esener, J. Mass Spectrom., 2013, 48, 768-773.

17 C. Sottani, G. Tranfo, M. Bettinelli, P. Faranda, M. Spagnoli and C. Minoia, Rapid Commun. Mass Spectrom., 2004, 18, 2426-2436.

18 J. B. Katzenmeyer, C. V. Eddy and E. A. Arriaga, Anal. Chem., 2010, 82, 8113-8120.

19 E. I. El-Kimary and A. F. El-Yazbi, Spectrochim. Acta, Part A, 2016, 163, 145-153.

20 Y. Liu and B. Danielsson, Anal. Chim. Acta, 2007, 587, 47-51.

21 E. Haghshenas, T. Madrakian and A. Afkhami, Anal. Bioanal. Chem., 2016, 408, 2577-2586.

22 R. Griss, A. Schena, L. Reymond, L. Patiny, D. Werner, C. E. Tinberg, D. Baker and K. Johnsson, Nat. Chem. Biol., 2014, 10, 598-603.

23 J. Y. Hou, T. C. Liu, G. F. Lin, Z. X. Li, L. P. Zou, M. Li and Y. S. Wu, Anal. Chim. Acta, 2012, 734, 93-98.

24 G. Lin, H. Zhao, T. Liu, J. Hou, Z. Ren, W. Huang, W. Dong and Y. Wu, RSC Adv., 2014, 4, 55229-55236.

25 Z. Q. Ren, T. C. Liu, J. Y. Hou, M. J. Chen, Z. H. Chen, G. F. Lin and Y. S. Wu, Luminescence, 2014, 29, 591-597.
26 J. W. Zhou, L. M. Lei, Q. N. Liang, T. C. Liu, G. F. Lin, Z. N. Dong, R. L. Liang, Z. H. Chen and Y. S. Wu, Clin. Biochem., 2015, 48, 603-608.

27 J. Y. Hou, T. C. Liu, Z. Q. Ren, M. J. Chen, G. F. Lin and Y. S. Wu, Analyst, 2013, 138, 3697-3704.

28 E. P. Diamandis and T. K. Christopoulos, Clin. Chem., 1991, 37, 625-636.

29 X. Dai, H. Xu, X. Zhang, W. Zhu, H. Gu and M. Wei, Mater. Sci. Eng., C, 2014, 34, 422-428.

30 C. Sottani, G. Poggi, F. Melchiorre, B. Montagna and C. Minoia, J. Chromatogr. B: Anal. Technol. Biomed. Life Sci., 2013, 915-916, 71-78.

31 W. Ma, J. Wang, Q. Guo and P. Tu, J. Chromatogr. B: Anal. Technol. Biomed. Life Sci., 2015, 1007, 18-22.

32 Z. Chao, M. Tan, M. K. Paudel, S. Sakamoto, L. Ma, K. SasakiTabata, H. Tanaka, Y. Shoyama, L. Xuan and S. Morimoto, J. Nat. Med., 2013, 67, 512-518.

33 X. Pei, B. Zhang, J. Tang, B. Liu, W. Lai and D. Tang, Anal. Chim. Acta, 2013, 758, 1-18.

34 P. A. Thompson, G. L. Rosner, K. K. Matthay, T. B. Moore, L. R. Bomgaars, K. J. Ellis, J. Renbarger and S. L. Berg, Cancer Chemother. Pharmacol., 2009, 64, 243-251.

35 S. Callies, D. P. de Alwis, J. G. Wright, A. Sandler, M. Burgess and L. Aarons, Cancer Chemother. Pharmacol., 2003, 51, 107118.

36 N. E. Kontny, G. Wurthwein, B. Joachim, A. V. Boddy, M. Krischke, U. Fuhr, P. A. Thompson, M. Jorger, J. H. Schellens and G. Hempel, Cancer Chemother. Pharmacol., 2013, 71, 749-763.

37 K. Kunarajah, S. Hennig, R. L. G. Norris, M. Lobb, B. G. Charles, R. Pinkerton and A. S. Moore, Cancer Chemother. Pharmacol., 2017, 80, 15-25.

38 Q. Zhang, X. Chen, F. Tu and C. Yao, Biosens. Bioelectron., 2014, 59, 377-383.

39 Z. L. Ge, T. M. Song, Z. Chen, W. R. Guo, H. P. Xie and L. Xie, Anal. Chim. Acta, 2015, 862, 24-32.

40 H. Tang, J. Chen, L. Nie, Y. Kuang and S. Yao, Biosens. Bioelectron., 2007, 22, 1061-1067.

41 Y. Zhou, Z. Xu, M. Wang, X. Meng and H. Yin, Electrochim. Acta, 2013, 96, 66-73.

42 M. Li, Y. Zheng, W. Liang, Y. Yuan, Y. Chai and R. Yuan, Chem. Commun., 2016, 52, 8138-8141.

43 Q. Zhou, G. Li, Y. Zhang, M. Zhu, Y. Wan and Y. Shen, Anal. Chem., 2016, 88, 9830-9836.

44 H. Tang, J. Chen, L. Nie, Y. Kuang and S. Yao, Biosens. Bioelectron., 2007, 22, 1061-1067. 